\title{
Serum levels of vitamin A, visual function and ocular surface after bariatric surgery
}

\author{
Luana Paula Nogueira de Araújo BRANDÃO, Lucio VILAR, Bernardo Menelau CAVALCANTI, \\ Pedro Henrique Amorim BRANDÃO, Tiago Eugênio Faria e ARANTES and \\ Josemberg Marins CAMPOS*
}

\begin{abstract}
Background - Bariatric surgery is the most effective treatment for severe obesity, but the surgery increases the risk of developing nutritional deficiencies, such as vitamin A deficiency. In human metabolism, vitamin A plays a role in vision. Objective - To evaluate serum vitamin A, visual function and ocular surface of patients undergoing bariatric surgery. Methods - A cross-sectional and analytical study was conduced with 28 patients undergoing bariatric surgery for at least 6 months. Ophthalmologic evaluation was done through color vision test, contrast sensitivity test, ocular surface tests and confocal microscopy, as well as vitamin A serum measurement. Results - Vertical sleeve gastrectomy was performed in seven (25.0\%) patients and Roux-en-Y gastric by-pass in 21 (75.0\%). Mean serum vitamin A level was $1.7 \pm 0.5 \mu \mathrm{moL} / \mathrm{L}$. Most patients (60.7\%) had symptoms of dry eye. Five (17.9\%) patients had contrast sensitivity impairment and 18 (64.3\%) color vision changes. In the group of patients undergoing Roux-en-Y gastric by-pass, mean vitamin A levels were $1.8 \pm 0.6 \mu \mathrm{moL} / \mathrm{L}$, whereas they were $1.7 \pm 0.5 \mu \mathrm{moL} / \mathrm{L}$ in patients submitted to the restrictive technique vertical sleeve gastrectomy. The analysis of the influence of serum levels of vitamin A in the visual function and ocular surface was performed by Pearson correlation test and there was no significant correlation between any of the variables and vitamin A. Conclusion - There was no influence of the bariatric surgery technique used on serum vitamin A levels, on the visual function or on the ocular surface. Moreover, there was no correlation between serum levels of vitamin A and the visual function or the ocular surface changes.
\end{abstract}

HEADINGS - Bariatric surgery. Vitamin A deficiency. Night blindness. Xerophthalmia.

\section{INTRODUCTION}

Bariatric surgery is the most effective treatment for severe obesity. In spite of its good results concerning weight loss and control of comorbities ${ }^{(7)}$, it increases the risk of nutritional deficiency in vitamins and minerals, such as vitamin $\mathrm{A}^{(23)}$. Several causes are dependent on the technique used and may include vomits, reduced nutrients ingestion, food intolerance, reduced gastric secretion and detour of the intestinal absorption area ${ }^{(23)}$. In human metabolism, vitamin A plays a major role in vision, reproduction, immune function and cellular differentiation ${ }^{(13)}$.

The eye is the most sensitive organ to vitamin A deficiency ${ }^{(30)}$. Vitamin A has na important function in the embryologic development of the eye, and it is essential for the maintenance of normal vision, throughout life ${ }^{(10)}$. Vitamin A deficiency may deprive photoreceptor cells of its visual pigments and cause disorganization of the external segments of the retina photoreceptors ${ }^{(30)}$. In ocular surface, retinol plays an important role in the maintenance of the cornea integrity ${ }^{(22)}$. Low levels of vitamin A can cause dry eye and corneal ulceration with risk of visual impairment $t^{(30)}$.

Despite the established relation between vitamin A deficiency and ocular alterations, few studies have correlated nutritional deficiency after bariatric surgery with ocular problems, such as night blindness and ocular xerosis. To the best of our knowledge, no studies have clinically evaluated the eye surface of patients submitted to bariatric surgery. The main objective of this study was to evaluate the serum levels of vitamin A, visual function, and ocular surface of patients submitted to bariatric surgery.

\section{METHODS}

This is a cross-sectional, observational and analytical study of patients aged 18-65 years old who had been submitted to bariatric surgery, within the last 6 months or longer. The exclusion criteria were: Sjögren Syndrome, corrected visual acuity worse than 20/40, opacities in the optical media, retinal lesion, choroid or optic nerve impairing vision, dyschromatopsia, glaucoma or glaucoma suspect, and previous intraocular surgery.

The study population was evaluated at Hospital de Olhos de Pernambuco (HOPE), State of Pernambuco, Brazil. The patients, who provided informed consent, were evaluated from February 2015 through December 2015, upon the project approval by the Fundação Altino Ventura Research Ethics Committee. The patients' data included: age, gender, body mass index (BMI), use of vitamin supplements, serum level of vitamin A, and clinical evaluation. The dosage of sérum vitamin A was accomplished at the same laboratory by means of high performance liquid chromatography. The pre-surgery BMI was obtained from medical records. 
The clinical evaluation initially tested the patients' refraction and assessed their visual acuity with better refraction correction. Next, patients were submitted to a color vision test and a contrast sensitivity test, which was measured in ideal illumination condition through Mars Letter Contrast Sensitivity test (Mars Perceptrix, Chappaqua, NY, USA). Log values of contrast sensitivity lower than 1.52 were considered abnormal. The color vision test performed was L'Anthony D15, with results expressed using concordance index. Values greater than or equal to 1.78 were considered high. Schirmer's test I and break-up time (BUT) were performed to measure the production of basal and reflex tear.

Schirmer's test I was considered normal for values higher than 10 $\mathrm{mm}$. Dry eye grading was classified as mild and moderate for values between 5 and $10 \mathrm{~mm}$, and severe for values lower than $5 \mathrm{~mm}$. BUT value was considered pathologic for results shorter than 5 seconds.

Ocular surface staining through fluorescein and rose bengal was used to detect áreas of keratitis. Van Bijsterveld's system was used to quantify the ocular surface staining. It divides the ocular surface into three zones: nasal bulbar conjunctiva, cornea and temporal bulbar conjunctiva. Each zone is evaluated in a scale from 0 to 3, with 0 indicating no staining and 3 indicating confluent staining. The maximum possible punctuation is 9 . The severity for rose bengal staining was classified as: normal (0-1), mild to moderate (2-6), or severe (7-9).

Ocular Surface Disease Index (OSDI) questionnaire was applied to the patients during the appointment. The test results were classified as normal (for values up to 12), minor symptoms (13-22), mild (23-32), or severe (33-100). Intraocular pressure was measured to make up for the ophthalmic exam of patients with widely known risk factors that increase intraocular pressure.

Confocal microscopy (Heidelberg Retina Tomography 3 - Rostock Cornea Module, Heidelberg Engineering, Germany, 2012) was performed to evaluate ocular surface and corneal layers. The preparation of the equipment consists of apposition of polymethyl methacrylate, filled with a layer of methylcellulose $2.5 \%$ in front of the objective lens. A topical anesthetic drop was instilled in both eyes, followed by hydroxypropyl methylcellulose $2.5 \%$. An external light font was used to maintain the patients' fixation.

The image capturing sequence mode was selected, and a total of six series was obtained per eye. The focus was modified according to the necessity to obtain images of the sub-basal nerves plexus and dendritic cells, which are normally situated in a depth of 50 $\mu \mathrm{m}$ to $80 \mu \mathrm{m}$ of the epithelium. All images were scanned and saved in a computer with restrict use.

The results of continuous variables were analyzed through means and standard deviations; the results of categorical variables were analyzed through absolute and relative frequencies. Data analysis was performed using statistical package SPSS version 16.0 (SPSS Inc., Chicago, Illinois, EUA). The $t$ test was used to assess mean difference per surgery type in case of variables with normal distribution; otherwise, Mann-Whitney U test was used. Pearson correlation coefficient was used to assess correlation between numerical variables. Statistical significance was set at $95 \%$ in all cases $(P<0.05)$ to reject the null hypothesis.

\section{RESULTS}

The sample consisted of 28 patients. Both eyes of each participant were included in the analysis, i.e. a total of 56 eyes. The patients' average age was $39.4 \pm 12.0$ years old; Twenty-two
$(22,78.6 \%)$ patients were females, and six $(21.4 \%)$ were males. The types of bariatric surgery patients were vertical gastrectomy $(7$, $25.0 \%$ ) and Roux-en-Y gastric derivation $(21,75.0 \%$ ) (Table 1).

TABLE 1. Characteristics of the sample patients

\begin{tabular}{ll}
\hline Age (years) $($ mean $\pm \mathrm{SD})$ & $39.4 \pm 12.0$ \\
Gender $[\mathrm{n}(\%)]$ & Female: $22(78,6 \%)$ \\
& Male: $6(21.4 \%)$ \\
Technique of bariatric surgery [n $(\%)]$ & Verical gastrectomy: \\
& $21(75.0 \%)$ \\
& RYGB: $7(25.0 \%)$
\end{tabular}

Post operative period (mean \pm SD), months $6.3 \pm 0.7$

$\mathrm{BMI}($ mean $\pm \mathrm{SD}), \mathrm{kg} / \mathrm{m}^{2} \quad$ Preoperative: $41.3 \pm 4.1$

Vitamin $A($ mean $\pm \mathrm{SD}), \mu \mathrm{moL} / \mathrm{L}$ Postoperative: $29.5 \pm 3.1$ $1.7 \pm 0.5$

Use of Vitamin A supplement [n (\%)]

Yes

$19(67.9 \%)$

No

$9(32.1 \%)$

SD: standard deviation; RYGB: Roux-en-Y gastric bypass; BMI: body mass index; $\mathrm{kg} / \mathrm{m}^{2}$ kilogram per square meter; $\mu \mathrm{mol} / \mathrm{L}$ : micromoles per liter.

Patients were evaluated in an average of $6.3 \pm 0.7$ months after bariatric surgery. During the evaluated period, the average serum level of vitamin A was $1.7 \pm 0.5$. The average BMI reduced from $41.3 \pm 4.1 \mathrm{~kg} / \mathrm{m}$ before surgery, to $29.5 \pm 3.1 \mathrm{~kg} / \mathrm{m}$ after surgery. Therefore, average BMI reduction was $11.8 \mathrm{~kg} / \mathrm{m}$ within a postoperative period of 6.3 months on average. (Table 1).

Most patients, $19(67.9 \%)$ used vitamin supplements with 5000 UI of vitamin A, whereas $9(32.1 \%)$ did not (Table 1). The average of vitamin A was $1.6 \pm 0.5 \mu \mathrm{mol} / \mathrm{L}$ in the group that used supplement and $1.9 \pm 0.5 \mu \mathrm{mol} / \mathrm{L}$ in the group without supplement. The differences, however, were not statistically significant. $(P=0.148)$.

Patients answered to an OSDI questionnaire and were classified according to dry eye symptoms. Most patients (60.7\%) reported some level of symptomatology. Scores were normal for $11(39.3 \%)$ patients, mild for $9(32.1 \%)$ patients, moderate for $1(3.6 \%)$ patient, and severe for $7(25.0 \%)$ patients.

Table 2 provides the findings of the visual function and ocular surface exams. Five $(17.9 \%)$ patients had altered contrast sensitivity, and $18(64.3 \%)$ had altered color vision in at least one eye. Schirmer's test I was abnormal in $9(33.3 \%)$ patients, mild to moderate in $5(55.55 \%)$ patients, and severe in $4(44.4 \%)$ patients.

TABLE 2. Distribution of patients' serum vitamin A, visual function and ocular surfasse tests, according to bariatric surgery technique (mean \pm SD)

\begin{tabular}{lccc}
\hline & VG & RYGB & $P$ \\
\hline Vitamin A, $\mathrm{PmoL}$ & $1.7 \pm 0.5$ & $1.8 \pm 0.6$ & $0.856 *$ \\
OSDI & $25.0 \pm 25.3$ & $23.7 \pm 32.5$ & $0.912 *$ \\
Color vision & $1.7 \pm 0.4$ & $2.3 \pm 1.0$ & $0.170 *$ \\
Contrast sensitivity & $1.7 \pm 0.1$ & $1.7 \pm 0.1$ & $0.640 * *$ \\
Schirmer's test I & $23.1 \pm 14.3$ & $26.0 \pm 13.8$ & $0.646 * *$ \\
BUT & $7.5 \pm 2.7$ & $6.7 \pm 3.6$ & $0.558^{*}$ \\
Fluorescein staining & $0.5 \pm 0.9$ & $1.0 \pm 1.4$ & $0.405 * *$ \\
Rose bengal staining & $1.1 \pm 1.3$ & $2.9 \pm 2.8$ & $0.162 *$ \\
Intraocular pressure & $13.0 \pm 2.6$ & $14.0 \pm 3.3$ & $0.421 *$ \\
\hline
\end{tabular}

* Student $t$ Test ** Mann-Whitney test. SD: standard deviation; VG: vertical gastrectomy; RYGB: Roux-en-Y gastric by-pass; $\mu \mathrm{mol} / \mathrm{L}$ : micromoles per liter; OSDI: Ocular Surface Disease Index; BUT: break-up time. 
BUT was shorter than 5 seconds in six $(21.4 \%)$ patients. Rose Bengal staining was indicative of dry eye in $22(39.3 \%)$ eyes; 20 (35.7\%) eyes with scores between 2 and 6, (i. e. from mild to moderate), and $2(3.6 \%)$ eyes with scores between 7 and 9 , i. e. severe dry eye (Table 3 ).

TABLE 3. Findings of ophthalmic exams

\begin{tabular}{|c|c|c|}
\hline & $\begin{array}{l}\text { Patients* } \\
(\mathrm{n}=28)\end{array}$ & $\begin{array}{c}\text { Eyes } \\
(\mathrm{n}=56)\end{array}$ \\
\hline \multicolumn{3}{|l|}{ Contrast sensitivity (log) } \\
\hline$\geq 1.52 \log ($ normal $)$ & $23(82.1 \%)$ & $50(89.3 \%)$ \\
\hline$<1.52 \log$ & $5(17.9 \%)$ & $6(10.7 \%)$ \\
\hline \multicolumn{3}{|l|}{ Color vision } \\
\hline$<1.78$ (normal) & $10(35.7 \%)$ & $28(50.0 \%)$ \\
\hline$\geq 1.78$ & $18(64.3 \%)$ & $28(50.0 \%)$ \\
\hline \multicolumn{3}{|l|}{ Schimer's test I } \\
\hline$>10 \mathrm{~mm}$ (normal) & $18(66.7 \%)$ & $41(75.9 \%)$ \\
\hline 5-10 mm (mild to moderate dry eye) & $5(18.5 \%)$ & $7(13.0 \%)$ \\
\hline$<5$ mm (severe dry eye) & $4(14.8 \%)$ & $6(11.1 \%)$ \\
\hline \multicolumn{3}{|l|}{ BUT } \\
\hline$\geq 5$ seconds (normal) & $22(78.6 \%)$ & $46(82.1 \%)$ \\
\hline$<5$ seconds & $6(21.4 \%)$ & $10(17.9 \%)$ \\
\hline \multicolumn{3}{|l|}{ Rose bengal staining } \\
\hline $0-1$ (normal) & $13(46.4 \%)$ & $34(60.7 \%)$ \\
\hline 2-6 (mild to moderate dry eye) & $14(50.0 \%)$ & $20(35.7 \%)$ \\
\hline 7-9 (severe dry eye) & $1(3.6 \%)$ & $2(3.6 \%)$ \\
\hline
\end{tabular}

* Percentage based on the worst eye. mm: millimeters; BUT: break-up time.

Patients were distributed into two groups according to bariatric surgery techinique, namely vertical gastrectomy and Roux-en-Y gastric derivation. Both groups had their results compared for serum vitamin A visual function and ocular surface test. There was no statistically significant between group-difference in any of the variables.

Pearson's correlation was used to analyze the influence of serum levels of vitamin A on visual function and ocular surface (Table 4). No statistically significant correlation was found between any of the variables and serum levels vitamin $\mathrm{A}$.

TABLE 4. Pearson's correlation analysis ( $\mathrm{r}$ ), for visual function, ocular surface tests and sérum levels of vitamin A

\begin{tabular}{lcc}
\hline Correlated variable to vitamin A & $\mathbf{r}$ & $P$ \\
\hline OSDI & -0.17 & 0.43 \\
Color vision & 0.25 & 0.25 \\
Contrast sensitivity & 0.09 & 0.68 \\
Schirmer's test I & 0.10 & 0.66 \\
BUT & 0.11 & 0.61 \\
Fluorescein staining & 0.08 & 0.72 \\
Rose bengal staining & -0.23 & 0.92 \\
Intraocular pressure & 0.22 & 0.31 \\
\hline
\end{tabular}

OSDI: Ocular Surface Disease Index; BUT: break-up time
A quantitative analysis of the confocal microscopy images pointed to no alteration in keratinocytes nor in the nerve fiber of the cornea (Figure 1). All corneal layers were considered normal by means of images evaluation (Figure 2).

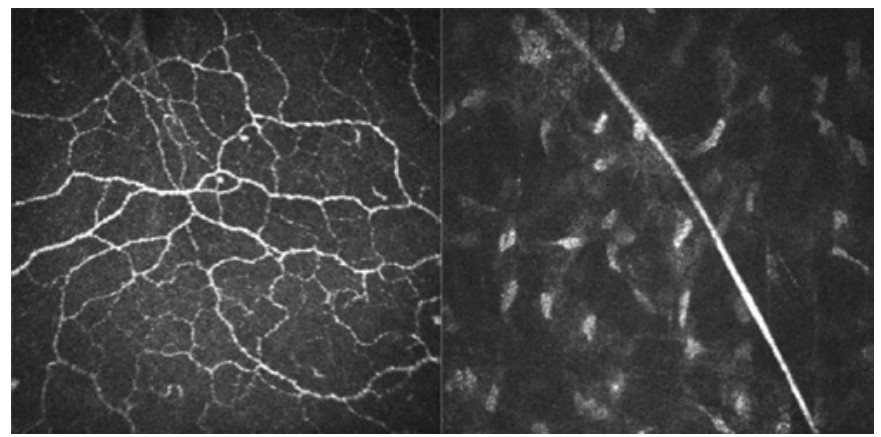

FIGURE 1. Confocal microscopy of nerve fiber from sub epithelial plexus and anterior stromal of the cornea

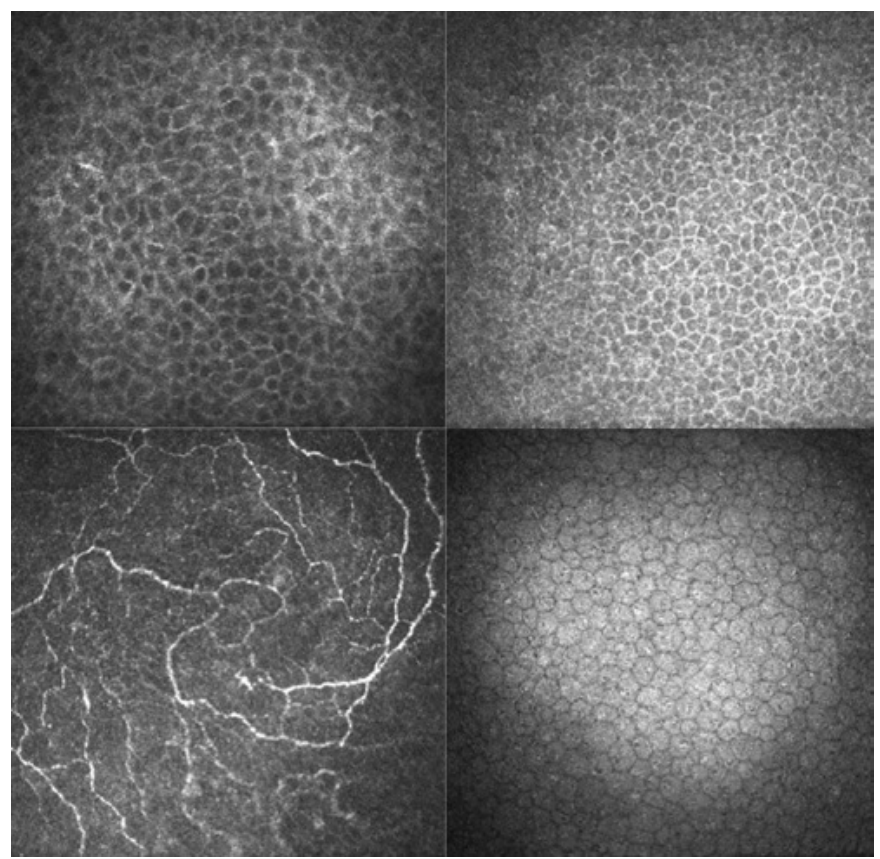

FIGURE 2. Confocal microscopy of corneal layers: intermediate epithelium, basal epithelium, central nerves and endothelium

\section{DISCUSSION}

Bariatric surgery is the most effective treatment for morbid obesity $^{(7)}$. In the postoperative follow-up; patients present an increased risk of nutritional deficiency of vitamins and minerals. Among the several causes might be: vomits, reduced nutrients ingestion, food intolerance, reduced gastric secretion and detour of the intestinal absorption area ${ }^{(23)}$. Vitamin A is an essential soluble compound that plays a major role in vision, reproduction, immune function and cellular differentiation in the human body ${ }^{(13,19)}$.

Whether bariatric surgery is performed or not, excessive weight has been considered a risk factor to nutritional deficiency, including antioxidant factors and some soluble vitamins, such as vitamin $\mathrm{A}^{(26,2)}$. The average prevalence of vitamin $\mathrm{A}$ before bariatric 
surgery reported in articles is $14.0 \%$. The causes of these nutritional deficiencies are not widely known, but are influenced by ingestion of processed food with high calorie associated with poor nutritional quality ${ }^{(28)}$. Some authors have pointed to a relation between BMI and vitamin A levels ${ }^{(19,27)}$

Serum level of vitamin A is considered adequate when it is higher than $1.05 \mu \mathrm{mol} / \mathrm{L}$, while levels lower than this may indicate deficiency. The average serum level of vitamin A in the sample was $1.8 \pm 0.5 \mu \mathrm{mol} / \mathrm{L}$, i.e, within the normal range. The literature has reported na average level of vitamin A of $1.66 \mu \mathrm{mol} / \mathrm{L}$ before bariatric surgery, $1.25 \mu \mathrm{mol} / \mathrm{L}$ after 30 days of intervention, and $1.53 \mu \mathrm{mol} / \mathrm{L}$ after 18 months $^{(1,8,9,15,16,19,25)}$.

Considering only patients submitted to DGYR, the average level of vitamin A was $1.8 \pm 0.6 \mu \mathrm{mol} / \mathrm{L}$. The literature has reported an average of $1.23 \mu \mathrm{mol} / \mathrm{L}$ within 30 days after surgery and 1.54 $\mu \mathrm{mol} / \mathrm{L} 18$ within months. In other words, there is a decline within 30 days after DGYR, followed by an increase within 18 months of follow-up, reaching a value close to that recorded before surgery $^{(8,9,15,16,19,20,25,29)}$.

Patients submitted to vertical gastrectomy had an average of vitamin $\mathrm{A}$ of $1.7 \pm 0.5 \mu \mathrm{mol} / \mathrm{L}$ with no statistically significant difference from those submitted to DGYR. Coupaye ${ }^{(8)}$ reported that 21 patients submitted to adjustable gastric banding surgery had, on average, $2.01 \mu \mathrm{mol} / \mathrm{L}$ and $2.15 \mu \mathrm{mol} / \mathrm{L}$ serum level of vitamin A before surgery and within 18 months after the procedure, respectively (i.e., an average increase of $0.14 \mu \mathrm{mol} / \mathrm{L}$ ) ${ }^{(8)}$.

Most patients studied used vitamin supplement with $5000 \mathrm{UI}$ of vitamin A, but differences were not statistically significant between this group and the one wich did no use supplement. Pereira et al. ${ }^{(19)}$ found persistent retinol and betacarotene deficiency in patients submitted to bariatric surgery, even after six months using vitamin supplement of retinal acetate.

In general the vitamin supplements used by patients which has undergone bariatric surgery offered a 5000 UI dosage of retinal acetate, which corresponds to twice the daily ingestion of vitamin A recommended to a normal individual ${ }^{(19)}$. However, like vitamin A and carotenoids, supplements are solubilized and absorbed in the small intestine; hence, their absorption is altered by the surgery likewise ${ }^{(5)}$.

In human metabolism, vitamin A plays a major role in vision, reproduction, imune function and cellular differentiation ${ }^{(13)}$. It is essential in the maintenance of the conjunctiva and corneal epithelium, phototransduction retinal and viability of the epithelial cells of the retinal pigment epithelium ${ }^{(24)}$. Night Blindness is a common complication of vitamin A deficiency ${ }^{(6)}$.

The patients'visual function was assessed through color vision and contrast sensitivity tests. The contrast sensitivity was altered in six patients $(17.9 \%)$ and color vision was abnormal in 18 patients $(64.3 \%)$. Pereira et al. ${ }^{(18)}$ assessed patients that had undergone DGYR and found out that the percentage of patients with night vision change was $22.3 \%$ before bariatric surgery and 59\% within 6 months after surgery. In another study ${ }^{(12)}, 68 \%$ of patients reported changes in night vision within six years after DGYR on average.

In the present study, $28.6 \%$ of the patients submitted to DGYR had a change of contrast sensitivity and $85.7 \%$ had color vision change. Comparing visual function among patients submitted to vertical gastrectomy and those submitted to DGYR, the average contrast sensitivity was equal in both groups, while the average color vision was worse in the DGYR group. However, there differences were not statistically significant.
In the IDSO questionnaire, most patients $(60.7 \%)$ reported dry eye symptoms. Eckert et al. ${ }^{(12)}$ applied a questionnaire on ocular symptoms to patients submitted to bariatric surgery for over one year before: $99 \%$ reported visual impairment and 38\% xerosis after the procedure.

Genead et al. ${ }^{(14)}$ reported a case in which a patient had symptoms of night blindness and deficiency of vitamin A 32 years after bariatric surgery. Salvo et al. ${ }^{(11)}$ reported a similar case of night blindness and dry eye after 35 years of bariatric surgery procedure. López-Rodríguez et al. ${ }^{(17)}$ described a case of important xerophthalmia associated with night blindness 2 years after bariatric surgery; the patient reported a feeling of strange body and hyperemia Ramos-Levi et al. ${ }^{(21)}$ found the same symptoms shown by López-Rodríguez et al. ${ }^{(17)}$ in a patient submitted to three bariatric interventions due to failure of the initial procedures.

Schirmer's test I showed that $66.7 \%$ of patients had no dry eye and TRFL was normal in $78.6 \%$. Most patients $(53.6 \%)$, had altered rose bengal staining. However, no relation was found of these exams with serum concentration of vitamin A and with surgery type.

A systematic review has shown that the association between clinical signs of dry eye and symptoms described by patients is low and inconsistent ${ }^{(4)}$. Similar results have been highlighted in a study carried out with 635 patients with dry eye: the concordance rate was too low among Schirmer's test I, rose bengal staining, accumulation of fluorescein and TRFL test ${ }^{(18)}$.

The use of confocal microscopy in vivo allows the visualization of the cornea in nearly histological cuts and has become a widely used tool to evaluate diseases and changes caused by eye surgery. Recent studies have shown the feasibility of using this technology to analyze the subepitelial nerve plexus of the cornea in patients without ocular alterations ${ }^{(2,3)}$. Morphologically, alterations were not observed in the corneal layers analyzed through confocal microscopy. No data of confocal microscopy in patients submitted to bariatric surgery has been reported in literature for comparison purposes.

Considering the high incidence of obesity worldwide and the consequent increase in bariatric surgery rates, it is important to gain a better understanding of its possible complications in order to established preventive programs at an early stage. This study will probably awaken the interest in investigating vitamin A levels in patients submitted to bariatric surgery. A number of aspects need to be clarified, which requires study designs involving comparison to control group, tardy evaluation within five years after surgery, and comparisons considering pregnancy and age groups.

\section{CONCLUSION}

Bariatric surgery technique (vertical gastrectomy or Roux-enY gastric derivation) did not have any impact on serum levels of vitamin A, visual function, or ocular surface. No correlation was found between serum levels of vitamin $\mathrm{A}$ and visual function.

\section{Authors' contributions}

Brandão LPNA: data collection, research execution, article writing. Vilar L: article writing. Cavalcanti BM: data collection, research execution, article writing. Brandão PHA: article writing. Arantes TEF: data collection, research execution, article writing, statistical analysis. Campos JM: data collection, article writing. 
Brandão LPNA, Vilar L, Cavalcanti BM, Brandão PHA, Arantes TEF, Campos JM. Níveis séricos de vitamina A, função visual e superfície ocular após cirurgia bariátrica. Arq Gastroenterol. 2017,54(1):65-9.

RESUMO - Contexto - A cirurgia bariátrica é o tratamento mais efetivo para obesidade grave, entretanto aumenta o risco de desenvolvimento de deficiência de nutrientes, como vitamina A. No metabolismo humano, a vitamina A exerce função importante na visão. Objetivo - Avaliar níveis séricos de vitamina A, função visual e superfície ocular de pacientes submetidos à cirurgia bariátrica. Métodos - Estudo transversal e analítico. População de 28 pacientes submetidos à cirurgia bariátrica há pelo menos 6 meses. Foi feita avaliação oftalmológica por meio de teste de visão de cores, teste de sensibilidade ao contraste, acuidade visual com correção, testes de superfície ocular e microscopia confocal, além da dosagem de vitamina A sérica. Resultados - Sete $(25,0 \%)$ pacientes foram submetidos à gastrectomia vertical e 21 (75,0\%), à derivação gástrica em Y de Roux. A média do valor sérico de vitamina A foi de 1,7 $\pm 0,5 \mu \mathrm{moL} / \mathrm{L}$. A maioria dos pacientes $(60,7 \%)$ apresentavam sintomas de olho seco. Cinco (17,9\%) pacientes apresentaram alteração da sensibilidade ao contraste e 18 (64,3\%) alteração da visão de cores. Quando considerados apenas os pacientes submetidos à derivação gástrica em $\mathrm{Y}$ de Roux, a média de vitamina $\mathrm{A}$ foi de 1,8 $\pm 0,6 \mu \mathrm{moL} / \mathrm{L}$, enquanto os submetidos à técnica gastrectomia vertical tiveram média de 1,7 $\pm 0,5 \mu \mathrm{moL} / \mathrm{L}$. A análise da influência dos níveis séricos de vitamina A na função visual e na superfície ocular foi realizada pelo teste de correlação de Pearson e não houve correlação significativa. Conclusão - Não houve influência do tipo de técnica de cirurgia bariátrica utilizada nos níveis séricos de vitamina A, na função visual, nem na superfície ocular. Da mesma forma, não houve correlação dos níveis séricos de vitamina $\mathrm{A}$ com a função visual nem com as alterações de superfície ocular.

DESCRITORES - Cirurgia bariátrica. Deficiência de vitamina A. Cegueira noturna. Xeroftalmia.

\section{REFERENCES}

1. Aasheim ET, Bjo S, Hanvold SE, Mala T, Olbers T, Bøhmer T. Vitamin status after bariatric surgery : a randomized study of gastric bypass and duodenal switch 1 - 3. Am J Clin Nutr. 2009;90:15-22.

2. Al-Aqaba M, Alomar T, Lowe J, Dua HS. Corneal nerve aberrations in bullous keratopathy. Am J Ophthalmol. 2011;151:840-9.e1.

3. Al-Aqaba MA, Faraj L, Fares U, Otri AM, Dua HS. The morphologic characteristics of corneal nerves in advanced keratoconus as evaluated by acetylcholinesterase technique. Am J Ophthalmol. 2011;152:364-76.e1.

4. Bartlett JD, Keith MS, Sudharshan L, Snedecor SJ. Associations between signs and symptoms of dry eye disease: a systematic review. Clin Ophthalmol. 2015;9:1719-30.

5. Blomhoff R. Transport and metabolism of vitamin A. Nutr Rev. 1994;52(2 Pt 2):S13-23.

6. Blomhoff R, Green MH, Norum KR. Vitamin A: physiological and biochemical processing. Annu Rev Nutr. 1992;12:37-57.

7. Buchwald H, Oien DM. Metabolic/bariatric surgery Worldwide 2008. Obes Surg. 2009;19:1605-11.

8. Coupaye M, Puchaux K, Bogard C, Msika S, Jouet P, Clerici C, et al. Nutritional consequences of adjustable gastric banding and gastric bypass: A 1-year prospective study. Obes Surg. 2009;19:56-65.

9. Dalcanale L, Oliveira CPMS, Faintuch J, Nogueira MA, Rondó P, Lima VMR, et al. Long-Term Nutritional Outcome After Gastric Bypass. Obes Surg. 2010;20:181-7.

10. Das BC, Thapa P, Karki R, Das S, Mahapatra S, Liu T-C, et al. Retinoic acid signaling pathways in development and diseases. Bioorg Med Chem. 2014;22:673-83.

11. De Salvo G, Maguire JI, Lotery AJ. Vitamin A deficiency-related retinopathy after bariatric surgery. Graefes Arch Clin Exp Ophthalmol. 2012;250:941-3.

12. Eckert MJ, Perry JT, Sohn VY, Boden J, Martin MJ, Rush RM, et al. Incidence of low vitamin A levels and ocular symptoms after Roux-en-Y gastric bypass. Surg Obes Relat Dis. Elsevier Inc. 2010;6:653-7.

13. Frey SK, Vogel S. Vitamin A metabolism and adipose tissue biology. Nutrients. 2011;3:27-39.

14. Genead MA, Fishman GA, Lindeman M. Fundus white spots and acquired night blindness due to vitamin A deficiency. Doc Ophthalmol. 2009;119:229-33.

15. Granado-Lorencio F, Herrero-Barbudo C, Olmedilla-Alonso B, Blanco-Navarro I, Pérez-Sacristán B. Hypocarotenemia after bariatric surgery: a preliminary study. Obes Surg. 2009; 19:879-82.

16. Granado-Lorencio F, Simal-Antón A, Blanco-Navarro I, González-Dominguez T, Pérez-Sacristán B. Depletion of serum carotenoid and other fat-soluble vitamin concentrations following obesity surgery. Obes Surg. 2011;21:1605-11.
17. López-Rodríguez N, Faus F, Sierra J, Ballarín T, Pueyo M, Albalad E. Night blindness and xerophthalmia after surgery for morbid obesity. Arch Soc Esp Oftalmol. 2008;83:133-5.

18. McCarty CA, Bansal AK, Livingston PM, Stanislavsky YL, Taylor HR. The epidemiology of dry eye in Melbourne, Australia. Ophthalmology. 1998; 105:1114-9.

19. Pereira S, Saboya C, Chaves G, Ramalho A. Class III obesity and its relationship with the nutritional status of vitamin A in pre- and postoperative gastric bypass. Obes Surg. 2009; 19:738-44.

20. Pereira S, Saboya C, Ramalho A. Impact of different protocols of nutritional supplements on the status of vitamin A in class III obese patients after Roux-en-Y gastric bypass. Obes Surg. 2013;23:1244-51.

21. Ramos-Levi AM, Perez-Ferre N, Sanchez-Pernaute A, Torres Garcia AJ, Rubio Herrera MA. Severe vitamin A deficiency after malabsortive bariatric surgery. Nutr Hosp. 2013;28:1337-40.

22. Rask L, Geijer C, Bill A, Peterson PA. Vitamin A supply of the cornea. Exp Eye Res 1980;31(2):201-11. [Internet]. Available from: http://www.ncbi.nlm.nih.gov/ pubmed/6432010

23. Schweiger C, Keidar A. Nutritional deficiencies in bariatric surgery patients: prevention, diagnosis and treatment. Harefuah. 2010;149:715-20, 748.

24. Sommer A. Xerophthalmia, keratomalacia and nutritional blindness. Int Ophthalmol. 1990;14:195-9.

25. Søvik TT, Aasheim ET, Taha O, Engström M, Fagerland MW, Björkman S, et al. Weight loss, cardiovascular risk factors, and quality of life after gastric bypass and duodenal switch: a randomized trial. Ann Intern Med. 2011;155:281-91.

26. Strauss RS. Comparison of serum concentrations of alpha-tocopherol and beta-carotene in a cross-sectional sample of obese and nonobese children (NHANES III). National Health and Nutrition Examination Survey. J Pediatr. 1999; $134: 160-5$.

27. Viroonudomphol D, Pongpaew P, Tungtrongchitr R, Changbumrung S, Tungtrongchitr A, Phonrat B, et al. The relationships between anthropometric measurements, serum vitamin A and E concentrations and lipid profiles in overweight and obese subjects. Asia PacJClinNutr. 2003;12:73-9.

28. Xanthakos SA. Nutritional deficiencies in obesity and after bariatric surgery. Pediatr Clin North Am. 2009;56:1105-21.

29. Zalesin KC, Miller WM, Franklin B, Mudugal D, Rao Buragadda A, Boura J, et al. Vitamin A Deficiency after Gastric Bypass Surgery: An Underreported Postoperative Complication. J Obes. 2011;2011:4-7.

30. Zhong M, Kawaguchi R, Kassai M, Sun H. Retina, retinol, retinal and the natural history of vitamin A as a light sensor. Nutrients. 2012;4:2069-96. 